\title{
Rationale for a climate club embedded in Article 6 of the Paris Agreement - a pathway to carbon neutrality
}

\author{
Michele Stuaa ${ }^{a}$, Colin Nolden ${ }^{\mathrm{b}, c *}$, Michael Coulon $^{\mathrm{d}}$
}

$a=$ Professional Affiliate, Institute of Management, Scuola Superiore Sant'Anna, Piazza Martiri della Liberta 24, Pisa, 56127, Italy michele.stua@gmail.com

$\mathrm{b}=$ Researcher, Environmental Change Institute, University of Oxford, 3 South Parks Road, Oxford, OX13QY, UK colin.nolden@ouce.ox.ac.uk

$c=$ Research Fellow, Law School, University of Bristol, 8-10 Berkeley Square, Bristol, BS8 1HH, UK colin.nolden@bristol.ac.uk

$d=$ Honorary Senior Lecturer, School of Business Management and Economics, University of Sussex, BN19RH, UK m.coulon@sussex.ac.uk

* = corresponding author colin.nolden@ouce.ox.ac.uk

Recent times have witnessed an increasing number of countries and private firms pledging carbon neutrality by mid-century. Whilst representing a significant improvement in intentions to tackle climate change, such pledges lack substance and structure. For instance, individual pledges lack coordination and aggregation among peers, while strategies and measures to achieve ambitious targets are largely absent. Moreover, current disagreements obstructing progress in international climate change negotiations further undermine the reliability of carbon neutrality objectives.

Effective international policies are needed to foster aggregate mitigation ambitions and the creation of adequate supporting mechanisms. This theoretical paper describes a governance innovation aimed at overcoming such shortfalls and disagreements through a unifying yet customizable pathway towards carbon neutrality. It does so by first outlining a political governance framework based on a climate club interpretation of Article 6 of the Paris Agreement. Secondly, it proposes carbon emission mitigation effort sharing on a per capita basis to ensure efficiency, equity and political feasibility. Thirdly, this paper describes how the supply of certified mitigations of carbon emissions required to satisfy effort sharing-based demand can be assetized as carbon credits by operationalizing Article 6 as a joint certification mechanism. The resulting governance architecture for managing demand and supply of mitigations shifts efforts to tackle climate change from a 'problem-driven' cost approach to 'opportunity-driven' value creation pathways towards carbon neutrality.

\section{Highlights}

- Climate clubs enable operationalisation of Article 6 of the Paris Agreement

- Effort-sharing on a per capita basis ensures a fair target distribution

- A joint certification mechanism mirrors effort-sharing in a climate club

- The resulting architecture provides a pathway towards carbon neutrality 


\section{Keywords}

Climate clubs; Article 6 of the Paris Agreement; assetization; effort-sharing; joint certification mechanism; carbon neutrality.

\section{Introduction}

Carbon neutrality requires absolute decoupling of carbon emissions from economic growth (IPCC 2018; Welch and Southerton 2019). This in turn requires spatially and temporally flexible and adjustable emissions mitigation governance and action at multiple levels, ranging from political and monetary governance to individual and collective action (Cœuré 2018; Raworth 2018; IMF 2019).

Decoupling of carbon emissions from economic growth has been driven by two common carbon emission mitigation policy instruments: a) regulatory measures (such as renewable energy support policies) and b) carbon pricing (Michaelowa et al. 2019). However, many policy instruments that fall under these categories are associated with distributional unfairness (Granqvist and Grover 2016). It is commonly assumed that absolute decoupling will require some form of global carbon pricing, which usually involves taxation (polluter-pays-principle) and/or cap-and-trade systems (grandfathering-principle) (Grubb 2014).

Taxation is unpopular and associates the reduction of pollution with a burden while the grandfathering-principle underlying cap-and-trade systems such as the Emission Trading Schemes (ETS) "states that the right to pollute today and in the future should be distributed in proportion to the amount of pollution agents have emitted in the past" (Granqvist and Grover 2016: 91; Nordhaus 2015). Although auctioning creates a competitive incentive structure, such systems typically reward historical pollution, especially where exemptions apply to heavy industry (Drews and van den Bergh 2016; Baranzini and Carattini 2017). They also place value on the 'right to emit' (Bowers 1997; Veal and Mouzas 2012). Such 'problem-driven' policy instruments have the connotation of a necessary evil and approach mitigation from a cost perspective (Stern 2007; Sovacool and Geels 2016; Michaelowa et al. 2019).

These approaches also fail to take historical transformation processes into account, which were 'opportunity-driven' (Sovacool and Geels 2016). Effective and flexible approaches to radical decarbonisation in line with the Paris Agreement require mission-oriented, systemic and innovative market mechanisms 'driven by opportunity' (Grubb 2014; Soovacool and Geels 2016; Mazzucato 2018; Michaelowa et al. 2019; UNEP 2019). This paper proposes a governance framework for climate clubs based on Article 6 of the Paris Agreement. It allows willing countries to pursue ambitious climate change mitigation targets by shifting the emphasis from a 'problem-driven' cost approach to 'opportunity-driven' value creation pathways towards carbon neutrality.

Such clubs have been theorised as the means to overcome free-riding, raise ambition and foster collective action (Weischer et al. 2012; Das 2015; Nordhaus 2015; Falkner 2016; Keohane et al. 2017; Pihl 2020). This paper, on the other hand, theorises a governance framework for climate clubs based on Article 6 of the Paris Agreement. Potentially linked to already existing (i.e.: the European Union; the G20; ASEAN; OPEC) and/or ad hoc alliances, this framework overcomes the limitations of Nationally Determined Contributions (NDCs) through collective targets distributed among carbon club members. It synthesizes governance innovation, an effort sharing system and a joint certification mechanism to shift decarbonisation from 'problem' towards 'opportunity'. It does so by changing the emphasis from the cost of mitigating carbon emissions towards the value of mitigating carbon emissions through the reducer-receives-principle, ultimately leading to the adoption of 'Positive Carbon Pricing' (Sirkis et al. 2015; Stua and Nolden 2019; Nolden and Stua 2020). 
Based on Stua's (2017a) interpretation of Article 6 of the Paris Agreement, this framework in principle facilitates the assetization of all forms of mitigation (reduction, capture/sink and avoidance) of anthropogenic greenhouse gases (GHG) as certified carbon credits within the boundaries of a climate club. By turning all GHG mitigations into identical, certified and fungible carbon credit units, this framework allows conventional carbon pricing approaches, including taxation and cap-and-trade systems, to be simplified and unified under a single, joint certification mechanism. To this end, this paper provides the legal basis for a climate clubs interpretation of Article 6 which facilitates the assetization of carbon emission mitigations as carbon credits.

Furthermore, this joint certification mechanism facilitates market, hybrid and non-market approaches to withdrawing carbon credits. This ensures transparency, effectiveness and alignment with Article 6. We shall subsequently describe the corresponding certification mechanism to create demand and supply of associated carbon credits. This provides the basis for a system of supply and demand which facilitates contraction and convergence of countries' per capita and absolute carbon emissions, by applying principles of distributional fairness (see Meyer 2000).

The paper is structured as follows: Section 2 introduces the theoretical assumptions of the governance architecture described in this paper. Section 3 suggests political governance innovations to operationalize a climate club system based on Article 6 of the Paris Agreement. Section 4 outlines the effort sharing system. Section 5 describes a joint certification mechanism to support and effectively mirror the effort sharing system. Section 6 concludes with a discussion concerning unresolved aspects of the theory and suggests future developments to facilitate its implementation.

\section{Theoretical assumptions}

According to Rogelj et al. (2016: 251), "no matter which approach is taken, the $\mathrm{CO}_{2}$ budget for keeping warming to below $2^{\circ} \mathrm{C}$ always implies stringent emission reductions over the coming decades and net zero $\mathrm{CO}_{2}$ emission in the long term". Increasingly, the international community is stressing the urgency to limit warming to below $1.5^{\circ} \mathrm{C}$ (IPCC 2021). These targets can be translated into carbon budgets regarding the volume of greenhouse gases which may be emitted during a certain period to limit warming, given the near linear relationship between such emissions and temperature rise (Clémençon 2016).

Due to the difficulty in estimating cumulative historical emissions (Friedlingstein et al. 2019), we use a method proposed by Clémençon (2016). This approach converts the Paris Agreement's $2 / 1.5^{\circ} \mathrm{C}$ objective into a carbon budget with a carbon neutrality target in the second half of the century. The carbon budget approach can be used to define specific budgets for members of potential climate clubs in relation to peak years to establish a baseline (Wei et al. 2014). Using baselines to determine policy actions, such as those underpinning carbon budgets, has been common practice in climate policy since the Kyoto Protocol (Stua 2017a: 11-12). Creating demand for the mitigation of carbon emissions to maintain the carbon budget depends on the embedding of robust baseline methodologies in such institutional arrangements.

Creating markets and redirecting economic activity using baselines, however, requires significant trust in, and reliability of, methodologies for measurement, reporting and verification, as well as certification mechanisms that can guarantee the permanence of carbon emission mitigations. The governance innovation described in this paper relies on effort sharing among climate club members to preserve the carbon budget and border carbon adjustments to delineate the climate club's carbon commons (Lacroix et al. 2015; Nolden and Stua 2020).

Carbon emissions mitigations represent non-excludable, intangible assets (Levi 1991; Clark and Knox-Hayes 2018). As public goods, such mitigations are therefore absent on domestic and corporate accounts. Savings in general, including financial or energy related savings, tend to be 
undervalued while increases in revenues are overvalued. Assetizing such mitigations is constrained by the transaction costs either of defining such mitigations as quasi-private goods or of trading them and enforcing quasi-property rights (Anderson and Parker 2013).

Assetization is "the turning of things into an asset" (Birch 2017: 462), a process of making things work in new ways in existing systems using a strong market logic (Dreyfuss and Frankel 2015). Value, valuation and the ability to capture rents result from a process of assetization (Birch 2017; Dreyfuss and Frankel 2015). The Clean Development Mechanism (CDM) did so by combining a system of demand based on the Kyoto Protocol's binding emission reduction targets with approved baseline methodologies to reduce the transaction costs of supply (Stua 2013).

Measuring and verifying carbon emission mitigations and of reorganizing this knowledge and evidence for assetization by delineating quasi-property rights involves costs, which are a function of available technologies as well as political and legal challenges of initiating institutional change (Anderson and Parker 2013). Recent improvements in data gathering infrastructures include cloud computing, remote sensors, smart meters, the Internet of Things (IoT), distributed ledgers, big data analytics, machine learning, satellite mapping and Artificial Intelligence (AI). These developments facilitate increasingly 'spatiotemporally granular' data capturing necessary for assetization (KraghFurbo and Walker 2018). Material qualities of existing monitoring equipment as well as sociotechnical configurations determine granularity and manageability (Kragh-Furbo and Walker 2018).

When combined, the refinement of baselines, carbon budget accounting and data producing and evaluation capacities can allow value to be created by time-stamping carbon emission mitigations and automatically assetizing them as quasi-private goods with well-defined and enforced quasiproperty rights. Key to assetizing carbon emission mitigations is the establishment of governance frameworks capable of creating demand. Transaction costs within such systems of demand are lowest when the attribute being sold and traded is uniform in nature and easily tracked, which enhances fungibility and liquidity (MacKenzie, 2009).

If the value of protecting the natural resource of atmospheric greenhouse gas emission carrying capacity conducive to preserving life on earth exceeds the expected costs of defining and enforcing quasi-property rights to this natural resource, it is assumed that a wide range of actors will establish new organisational structures, business methods and ways living to maintain this natural resource through the assetization of carbon emission mitigations (Anderson and Parker 2013). Such bold efforts to tackling climate change require innovative, equitable, fair and sustainable political governance of this natural carbon budget resource.

\section{Political governance innovation}

The Paris Agreement provides the legal framework for the establishment of international carbon market governance arrangements through a global carbon market in its Article 6 (Marcu 2016; Stua 2017a; Michaelowa et al. 2019; Mueller and Michaelowa 2019; Zhang et al. 2020). This section elaborates on Stua's (2017b) climate club interpretation of Article 6. Confirmed by a legal analysis by Peter Zaman (2017), an internationally renowned lawyer and former consultant for the World Bank, this interpretation provides the basis for establishing a governance framework to facilitate the assetization of carbon emission mitigations. Increasingly, organisations such as the World Bank also consider climate clubs based on Article 6 to be a means of unlocking ambition and facilitating participation by a range of subnational entities and private actors (Srinivasan and Sanchez 2020).

Article 6's opening paragraph states that "Parties recognize that some Parties choose to pursue voluntary cooperation in the implementation of their nationally determined contributions to allow for higher ambition in their mitigation and adaptation actions and to promote sustainable development and environmental integrity" (UNFCCC 2015). Despite its voluntary nature, Article 6 is 
considered crucial to operationalize the Paris Agreement given the lack of ambition evident in Nationally Determined Contributions (NDCs) and the yawning gap between rising carbon emission levels and the steep downward trajectory required to meet Paris Agreement objectives of implicit carbon neutrality (Mueller and Michaelowa 2019; Pihl 2020). In fact, voluntary elements in international legislation may hold much more power than ineffective 'binding' norms clashing against states' sovereignty (Zaman 2017). Moreover, this opening paragraph also represents the bridging element between climate clubs and the Paris Agreement (Stua 2017a: 52, 55-57).

Through its explicit and unique reference to "some Parties" (UNFCCC 2015), this paragraph creates a de facto option for cooperative strategies implemented by a smaller subset (or 'club') of signatories of the Paris Agreement. Such cooperative strategies and action enable the operationalization of a Paris Agreement objective-aligned climate club defined by Stua as a Mitigation Alliance (Stua 2017a; Stua 2017b). Finally, Article 6's opening paragraph provides the opportunity for associated climate club members to increase their shared ambitions compared to what is expressed in their NDCs. In Stua's interpretation this can lead to a club's common effort sharing equating to carbon neutrality (Stua 2017a: 61-61). This last and key aspect is further discussed in Section 4 of this paper.

Article 6.2 is often interpreted as the basis for developing common modalities for piloting activities, potentially under the auspices of a climate club (Greiner and Michaelowa 2018). It defines cooperative approaches for "internationally transferred mitigation outcomes" and is often seen as the ideal tool for bilateral exchanges and cooperation in addition to the NDCs (Dietzenbacher et al. 2020; Franke et al. 2020). Article 6.4 is often considered the basis for establishing a "mechanism" to implement carbon markets under the Paris Agreement (Schneider et al. 2020; Steinebach and Limberg 2021). Article 6.8 is considered the basis for separate "non-market mechanisms" (EBRD 2017; Asadnabizadeh 2019).

Operationalizing Article 6 as a unified instrument, on the other hand, allows for the establishment of a holistic climate governance architecture (Stua 2017a: 85-103). Such an interpretation suggests that Article 6 facilitates the establishment of a joint certification mechanism which applies to any form of carbon emission mitigation, including market, hybrid and non-market-based approaches, as long as they can be measured, reported and verified (MRV). It hinges upon an evolutionary perspective, which interprets the "sustainable development mechanism" (Article 6.4-6.7) as a radically innovative successor of the Clean Development Mechanism (Stua 2017a: 90-102). This interpretation recognises in Article 6 a means of certifying any mitigation in greenhouse gas emissions among Parties that voluntarily agree to do so through cooperation according to Article 6.2, which in turn delineates membership of an associated climate club. Instead of potentially competing paragraphs (see Michaelowa and Hoch 2016), this interpretation thus suggests that Article 6 can act as a mechanism for bilateral (Article 6.2), market (Article 6.4) and non-market (Article 6.8) approaches if it is implemented through a climate club with border carbon adjustments to overcome free-riding and reduce carbon leakage (Stua 2017a: 120-126; see also Nordhaus 2015).

Climate clubs, together with border carbon adjustments, can level the playing field between countries pursuing ambitious climate change targets and countries pursuing unilateral targets, or none at all (UNEP 2018; von der Leyen 2019). By levying carbon tariffs or taxes on imported goods according to their carbon footprint, border carbon adjustments guarantee climate club integrity by ensuring that the benefits of partaking in such a climate club only accrue to partaking countries, thereby reducing the free rider problem (Nordhaus 2015; Mehling et al. 2018; Nolden and Stua 2020).

Together with significant additional excludable environmental, economic and social benefits (Stua 2017a: 194), border carbon adjustments thereby act as a membrane delineating and protecting carbon commons inherent in the climate club, whilst simultaneously offering flexibility and space for 
achieving 'more' (ambition) with 'less' (multilateralism). Since the signing of the Paris Agreement, such clubs have been considered the ideal framework for operationalizing Article 6 (Stua 2017b; Pihl 2020), even if initially contested by some relevant clubs' scholars (Nordhaus 2020). In principle, a climate club based on this interpretation of Article 6 and delineated through border carbon adjustments is also capable of shifting the emphasis from the price and cost of reducing carbon emissions to the value of increasing carbon emission mitigations. Such "positive carbon pricing" (Sirkis et al. 2015) hinges upon:

- Assigning value to carbon emission mitigations by recognising atmospheric carbon-carrying capacity as an exhaustible natural resource;

- Establishing a timetable in which this exhaustible natural resource needs to be safeguarded;

- Creating demand for actions to protect this exhaustible natural resource; and

- Fair sharing of the remaining carbon budget.

According to Stua (2017a), the legal foundation and/or the emergence of these four steps are summarised below:

- Assigning value to carbon emission mitigations by recognising atmospheric carbon-carrying capacity as an exhaustible natural resource: The Paris Agreement provides a World Trade Organisation-compliant legal framework for establishing positive carbon pricing (Stua 2017a: 175-188; Stua et al. 2019). Article 2 of the Paris Agreement, as stated above requires signatory Parties to hold "the increase in the global average temperature to well below $2^{\circ} \mathrm{C}$ above pre-industrial levels and to pursue efforts to limit the temperature increase to $1.5^{\circ} \mathrm{C}$ above pre-industrial levels" (UNFCCC 2015). As the primary objective of the Paris Agreement, this provides the basis for recognizing atmospheric carbon-carrying capacity as an exhaustible natural resource while necessitating the reduction of carbon emissions to zero (carbon neutrality). Recognizing atmospheric carbon carrying capacity as an exhaustible natural resource requires the recognition of a global carbon budget (IPCC 2018). According to the IPCC (2018), the remaining carbon budget at the end of 2017 was $580 \mathrm{GtCO}_{2}$ for a $50 \%$ probability of limiting warming to $1.5^{\circ} \mathrm{C}$, and $420 \mathrm{GtCO}_{2}$ for a $66 \%$ probability.

- Establishing a timetable in which this exhaustible natural resource needs to be safeguarded: Another precondition for positive carbon pricing, the establishment of a timetable to safeguard this exhaustible natural resource, is also provided by the Paris Agreement. Its Article 4 clarifies that "each Party shall communicate a nationally determined contribution (NDC) every five years" (UNFCCC 2015). Ambition for mitigating carbon emissions will be ratcheted up according to these binding updates every 5 years. Demand for action to protect the exhaustible natural resource is also inherent in the $2^{\circ} \mathrm{C} / 1.5^{\circ} \mathrm{C}$ objective. In practical terms, demand for action, which is increasingly shaping Parties' carbon neutrality pledges (EC 2019), is determined by the value assigned to carbon emission mitigation (or through its mirror of carbon pricing).

- Creating demand for actions to protect this exhaustible natural resource: Assigning value to the protection of this exhaustible natural resource equates to recognizing assetized carbon emission mitigations as quasi-private goods. This enables measured, reported and verified (MRV) carbon emission mitigation units (i.e.:. $1 \mathrm{tCO}_{2}$ eq.) to be included in an international market pricing system, assigned a value (carbon pricing) and traded as a commodity with full fungibility. The specific timetable in which the atmospheric carbon carrying capacity needs to be safeguarded (inherent in Article 2) combined with the fixed ceiling of the resource (e.g.: $<420 / 580 \mathrm{GtCO}_{2}$ e 2011-2100) determine the price of carbon emission mitigation units supplied, traded and withdrawn in a positive carbon pricing environment (Sirkis et al. 2015; Stua 2017a: 177-184; Stua et al. 2019).

- Fair sharing of the remaining carbon budget and ecological space: Fair sharing of the remaining carbon budget hinges on the redistribution of carbon shares from wealthier to 
poorer nations (Holz et al. 2017; Stua 2017a: 75-81). The effort sharing system described below in section 4 supports contraction and convergence of per capita carbon emissions among the members of the climate club (see Meyer 2000).

Positive carbon pricing shifts the emphasis from the cost of limiting an environmental externality (the cost of reducing carbon emissions to minimize impact on the non-exhaustible resource of the atmosphere) towards the value of mitigating carbon emissions to protect an exhaustible natural resource (the atmospheric carbon carrying capacity). To take common but differentiated responsibilities and respective capabilities (CBDR-RC) between countries (UNFCCC 2015) and the Sustainable Development Goals (UNDP 2015) within countries into account, the political governance of positive carbon pricing needs to be underpinned by an equitable effort sharing system.

\section{Effort sharing system}

Five years after the signature of the Paris Agreement, its full implementation is still inhibited by a variety of unresolved issues. The biggest of these appears to be the alignment of Parties' mitigation efforts with the Paris Agreement's carbon neutrality objective (OECD 2019). Whilst the imposition of an orchestrated and collective effort, possibly taking into account crucial elements like the CBDR-RC principle, might have led to the failure to reach any deal in Paris in 2015, the solution proposed in Article 4 of the Paris Agreement has now demonstrated all of its limitations and weaknesses. By providing individual Parties full independence in defining any aspect of their mitigation efforts, the Agreement immediately fails to reach its ambitious objectives. Whilst some Parties have been trying to individually align their mitigation efforts with the Paris Agreement objective by pledging for carbon neutrality (EC 2019), their attempts ultimately fall short because: a) lack of governance, including policies and mechanisms, dedicated to their implementation; b) lack of coordination among individually managed pledges which hinders transparency and accountability; and c) lack of support to the CBDR-RC principle offered by the current pledges system (Rajamani 2016).

An adequate effort sharing system would overcome such obstacles (Li and Duan 2020). Yet, past experiences involving effort sharing have revealed significant limitations. For instance, the Kyoto Protocol (UNFCCC 1997) adopted a static and ideology-based effort sharing structure, which divided Parties into polluters with pollution reduction duties (Annex I) and those with the right to further pollute (non-Annex I). By excluding any adjustment over time, this system revealed its limitations. These were among the key issues that led to the failure of the COP15 negotiations in Copenhagen in 2009 (Blaxekjær and Nielsen 2014; Rajamani 2014; Nolden and Stua 2017).

Instead, emissions need to be shared equitably and effectively, especially among wealthy, highly developed and carbon-intense economies (Welch and Southerton 2019; Li and Duan 2020). Based on the findings and innovative approaches advocated in Stua and Coulon (2017), the here proposed system seeks to do so by ensuring that overall per capita consumption-based emissions among climate club members eventually 'contract and converge' towards carbon neutrality (Rajan 2019; Meyer 2000). By operationalizing the carbon neutrality target, this system can be used by national governments (and possibly sub-national entities) to stimulate spatially and temporally flexible institutional and organisational innovation around the assetization of carbon emission mitigations.

This can be achieved through Stua and Coulon's mathematical model (2017). By taking into account the climate club's combined carbon emissions at the climate club's entry into force (time zero, or $t_{0}$ ), a total amount of carbon emissions $\left(C_{t_{0}}\right)$ is determined, corresponding to the climate club's overall carbon emission mitigation target (henceforth $C$ ). This is the (theoretical) common and unifying goal for its members. This target will then be distributed over time (following Article 4 of the Paris Agreement) and assigned to members based on a dynamic formula explained below, which has been slightly updated since (Stua 2017a) but retains all core features and objectives. This formula allows 
"for higher ambition in [climate club members'] mitigation and adaptation actions and [promotes] sustainable development and environmental integrity" (Paragraph 1 of Article 6) according to CBDR$\mathrm{RC}$ criteria as well as transparency and environmental integrity requirements (according to Paragraph 2 of Article 6).

In principle, climate club members, following the rules contained in Article 4, can define time distribution a priori. Here, overall time $T$ anticipated for reaching the overall mitigation target $\mathrm{C}$ will be distributed in 5 -year timeframes $(t, t+1, \ldots t+n)$, with $t \leq t+1 \leq \ldots t+n$ in line with Article 4 , which states that signatories to the Paris Agreement are required to update their NDCs every 5 years. This enables ambitions to be ratcheted up over time, especially given the current shortfall between NDC ambition and the decarbonisation necessary to maintain a reasonable chance of limiting global average temperature rise to the Agreement's objectives (UNEP, 2018).

To each timeframe is assigned a portion of the overall mitigation target $C\left(C_{t}+C_{t+1} \ldots C_{t+n}=C\right)$. With timeframes corresponding to shares of $C$, quotas of each sub-target are then allocated to climate club members through the application of the following dynamic formula (to be repeatedly used at the beginning of each 5-year timeframe). The quota distribution system takes into account per capita emissions of each climate club member $\left(P C_{j, t}\right)$ as well as the climate club's aggregate per capita emissions $\left(P C A_{t}\right)$. The resulting values establish which members are responsible for which share of the club's mitigation target within a given timeframe. Only members with per capita emissions higher than the climate club average $\left(P C_{j, t}>P C A_{t}\right)$ are assigned non-zero quotas (mitigation targets) through the application of this formula.

Both members with and without assigned positive (non-zero) quotas (mitigation targets) are entitled to alter their individual emissions levels in each timeframe, with no pre-established limit or peak. As discussed below, any positive variation relative to the target in climate club's aggregate emissions in a timeframe will be compensated in the following timeframe through the adoption of the dynamic variations term $V_{t}$.

The following formula encapsulates the above by defining the mitigation target $M T_{j, t+1}$ (the share of the club's target assigned to timeframe $t+1$ ) for any member $j$ with per capita carbon emissions $P C_{j, t}$ greater than $P C A_{t}$ at the time $t$, and assigning a target of zero for all others (with $P C_{j, t} \leq P C A_{t}$ ):

$$
M T_{j, t+1}=\underbrace{\left(C_{t+1}+V_{t}\right)}_{\begin{array}{c}
\text { total reduction } \\
\text { target for club }
\end{array}} \times \underbrace{\frac{\max \left(0, P C_{j, t}-P C A_{t}\right) \times P_{j, t}}{U_{t}}}_{\text {member } j^{\prime} \text { s sha }} \text {, for } U_{t}=\sum_{i} \max \left(0, P C_{i, t}-P C A_{t}\right) \times P_{i, t}
$$

where $P C_{j, t}=E_{j, t} / P_{j, t}$ is the member's per capita carbon emissions (current emissions divided by current population) and $P C A_{t}$ is total emissions of the climate club divided by the total population of the entire climate club. The term $U_{t}$ represents the total emissions by which the higher emitting members lie above the club's per capita average, and is used to determine relative shares of the total emissions reductions to assign to each of these members. Mitigation targets $M T_{j, t+1}$ for the next timeframe are set at time $t$, the end of the previous timeframe.

The fraction representing the second half of the formula can be understood to be member $j$ 's total emissions above the climate club threshold divided by the sum of all such emissions across the identified responsible members; i.e. those whose per capita emissions are above the threshold of the climate club average per capita or $P C A_{t}$. It thus ensures the equitable distribution of the climate club's target of $\left(C_{t+1}+V_{t}\right)$ among its members with higher-than-average per capita emissions. The first half of the formula (the club's overall target) consists of two components: (i) the predetermined overall target $C_{t+1}$ matching the club's agreed emissions trajectory to limit temperature increase; and (ii) a dynamic 'variations' term $V_{t}$ defined as follows: 


$$
V_{t}=\max \left(0, \sum_{i}\left[E_{i, t}-\left(E_{i, t-1}-M T_{i, t}\right)\right]\right)
$$

Based upon data collected through the public registries referred to in Article 4 of the Paris Agreement and information provided by the global stocktake referred to in Article 14 of the Paris Agreement, the variations term $V_{t}$ guarantees environmental integrity of the model embodied by the climate club. $v_{t}$ accumulates any overall emissions growth from climate club members during the previous timeframe, as well as excess emissions from members who have missed their mitigation targets. This amount is then automatically reallocated to the entire club as part of the target for the following timeframe. $v_{t}$ thus guarantees environmental integrity of the model by adding all emissions to the demand for mitigations in future timeframes. To maintain a minimum target of $C_{t+1}$, a negative $V_{t}$ value is not applied to the timeframe $t+1$.

Changes in per capita emissions and population over time automatically alter the set of members with quotas (assigned targets) and their relative quotas' magnitudes in successive timeframes. This process implies that changes in per capita emissions, both at member and at aggregate levels, may move any climate club member from having a positive assigned target $M T_{i, t}$ to a zero target, or vice versa, in the following timeframe. Of course members may also accelerate their mitigation pathways voluntarily to counteract the move from having no quota to a positive quota, or to benefit from a quota decrease linked to per capita variations over the course of a timeframe.

This effort sharing system, closely aligned to the one proposed by Stua (2017a), would create demand among club's members to achieve full carbon neutrality in a specific timetable. This would happen through a process of contraction and convergence of its members' per capita and absolute emissions and would be completed over a total timetable of $T+5$ years, with $t+n+1$ representing the very last timeframe when $C_{t+n}$ is exhausted and the only amount of mitigation to be shared among the club's members corresponds to $V_{t+n+1}$. (i.e. $C_{t+n+1}=0$ )

If Parties were to adopt such a technocratic effort sharing system as members of a climate club they would be free to internally distribute and customize their quotas as they wish. In other words, each climate club member can independently design and adjust rules determining whether and how they are assigned to specific sectors/areas/groups of stakeholders acting inside their jurisdiction and how to facilitate the assetization of carbon emission mitigations. This can include any of the policy instruments for climate change mitigation identified by Grubb (2014) such as regulatory measures, carbon pricing through carbon taxation and ETS, and public investment support to mobilize innovation such as the European Green Deal (UNEP 2019; von der Leyen 2019).

In principle, members can satisfy their effort sharing obligations through any certified carbon emission mitigation, including reductions (typically associated with substituting polluting energy supply with clean energy supply and industrial innovation), avoidance (typically associated with reductions in energy and resource demand and phasing out polluting technologies and fuels), and sinks (typically associated with the maintenance of natural habitat, afforestation, reforestation, blue carbon and carbon capture and sequestration) Hence, the effort sharing system requires a mirror mechanism to certify the variety of mitigations capable of satisfying the system's own requirements, which has been described by Stua as a joint certification mechanism (Stua 2017a: 85-102). 


\section{Benefits of a joint certification mechanism}

As discussed in Section 3 of this paper, the common interpretation of Article 6 includes three separate approaches to both certifying and managing mitigation. This understanding creates obstacles that affect the full implementation of the Article and entire Agreement, including:

- Heterogeneity in certifying and/or managing mitigations and corresponding lack of transparency.

- High transaction costs.

As theorised by Stua (2017a: $85-108$ ), and recently recognised by some international institutions such as the Asian Development Bank (ADB 2019), adopting a joint certification mechanism to be used for any mitigation action can help overcome these obstacles as follows:

- A joint certification mechanism would lead to homogeneity by certifying any mitigation actions, regardless of their origin or use. Hence, a centralised certification mechanism would significantly increase overall accountability and transparency without compromising the opportunity for actors to freely manage certified credits.

- A joint certification mechanism would simplify the whole certification process, hence contributing to a significant reduction of transaction costs. By envisaging an increased adoption of digital technologies for certification (e.g., smart metering, GIS information, big data analytics, cloud computing, distributed ledger technologies), transaction costs may be further reduced, in some cases approaching zero.

A joint certification mechanism would not hinder the variety of opportunities linked to creating, managing and accumulating certified credits. Ultimately such credits are withdrawn to demonstrate emissions mitigations by the credits holders (hence satisfying the requirements created by the effort sharing system described in section 4). Up to that point, however, certified credits may be exchanged and traded through markets and/or bilateral agreements within the climate club (hence satisfying paragraphs 2 and 4 of Article 6). By stimulating the club's 'internal offsetting', this process would increase the value of certified credits and contribute to the enforcement of its overall governance architecture.

\section{Conclusions and policy recommendations}

Political governance innovation emerging out of climate clubs together with effort sharing and a bold mechanism unifying certification of any form of recognised mitigations as suggested in this paper represent a radical and effective pathway to operationalize Article 6 of the Paris Agreement. Together with its inherent incentive to achieve the club's carbon neutrality and the objective of the Paris Agreement, this architecture may ultimately facilitate wealth redistribution in favour of club members with low per capita carbon emission levels. As low per capita emissions are often linked to poor Human Development Index countries (Costa et al. 2011), this aspect represents the main driver for climate justice in Stua's proposal (Stua 2017a: 133-167). Moreover, the proposed joint certification mechanism requires increasing transparency and environmental integrity of the club's mitigation process (Stua 2017a: 85-103), all of which represent essential principles of the Paris Agreement.

Yet, academics and policy makers may identify potential uncertainties and weaknesses in the theorisation summarised in this paper, such as: a) the adherence of such a theorisation to the incumbent international legislation (i.e., the General Agreement on Trade and Tariffs); b) its 
interrelation with pre-2020 mitigation credits (i.e., the unexhausted credits generated by the Kyoto Protocol's (DM); c) the issue of double-counting credits; d) the ability for a voluntary club to reach an accountable level of self-enforcement; and e) the so-called 'trilemma' relating to critical mass.

Discussing in detail the potential solutions of these uncertainties and weaknesses is beyond the scope of this paper, which instead aimed to introduce Stua's (2017a) theorisation as a resource for climate clubs compliant with the Paris Agreement and, most importantly, to demonstrate their carbon neutrality potential. Nevertheless, this final section of the paper provides indicative answers to these questions and advocates strategies towards their full resolution. These can be derived from additional content from Stua's book (2017a: 133-199) and the potential implementation of piloting experimentation of these proposals.

The potential clash between the legal framework of Stua's theory and the international legislation (with special reference to the General Agreement on Trade and Tariffs) represent a core part of Chapter 8 of Stua's book (Stua 2017a: 140-144). Given its relevance and complexity (the book describes the governance architecture of the club), this part of the theory requires significant analysis, hence falling beyond the limited scope of this paper.

Another issue hinted at in Stua's book is the widely-debated issue of pre-2020 carbon credits' role in a future crediting architecture based on the Paris Agreement. This resulted in a series of clashes between countries traditionally holding CDM credits (i.e.: China, India and Brazil) and countries worried about the risks resulting from the 'cheap use' of such credits (i.e.: the European Union and other OECD members), has already been hinted at in Stua's book. More precisely, Stua theorised the adoption of such credits to enhance a hypothetical climate fund for stabilizing a resulting carbon market (Stua 2017a: 85-102, 149-167). This fund may also act as stabilizer against double-counting by becoming the reserve for credits between their issuance and their final withdrawal. Yet again, such a debate falls beyond the scope of this paper and requires additional analysis.

The voluntary nature of climate clubs under Article 6 implies that the proposed governance framework entails a weak system of enforcement. Its success or failure hinges entirely on club members' willingness to commit to a carbon neutrality target by sharing the effort of doing so in a system of supply and demand. The benefit of doing so lies in the possibility of creating demand for, and achievement of, carbon neutrality for the whole club. Yet this represents a non-excludable benefit which is beneficial beyond the club's boundaries (Levi 1991) and stimulates so-called freeriding (Nordhaus 2015; Falkner 2016). Following on from Weischer et al. (2012), Stua discusses the idea that enforcement for proposals such as this one comes from an extensive set of (economic, environmental and social) benefits accruing only within the club's jurisdiction and enjoyed exclusively by its members. Only partially introduced in Section 3 of this paper, these excludable benefits, which include but are not limited to the opportunity for the club to legally adopt border carbon adjustments against free-riding, represent the fundamental tools for the club's enforcement over time. Once again, this interesting part of Stua (2017a: 175-198) idea falls beyond the scope of this paper and requires further analysis.

Finally, several commentators argue that climate clubs need to reach a critical mass to be effective, which is referred to as the participation/ambition/compliance trilemma (Tørstad 2020). It contends that without participation of large emitters, climate clubs lack ambition, which in turn weakens the internal dynamic to achieve compliance. On the other hand, COP25 witnessed the emergence of a climate club on its penultimate day. In the early morning of 14 December 2019, nine Parities, led by Costa Rica and Switzerland, established the San José Principles based on Article 6 of the Paris Agreement to ensure environmental integrity and increase carbon emission mitigation ambitions. The progressive countries that constitute the San José Principles thus established a climate club with the intention to deliver an overall mitigation in global emissions, avoid double counting of emission 
reductions and fully apply the principles of transparency, accuracy, consistency, comparability and completeness (Michaelowa 2019; Agedas Ortiz 2020).

The San José Principles initiative suggests that, at least during an initial phase, the participation/ambition/compliance trilemma can be addressed through a climate club without a critical mass. This empirical evidence of the potential operationalization of an Article 6 based climate club regardless of its initial size confirms the strength and feasibility of Stua's (2017a) theorisation. In particular, it clearly applies to the San José Principles and supports carbon neutrality for its climate club members (see above section 3), regardless of the club's size. Moreover, the theory supports an inclusive architecture aimed at facilitating and stimulating new members to join the club over time (Stua 2017a: 103).

To conclude we suggest that this radically innovative theorisation can be fully enhanced through additional theoretical studies and, above all, through actual and empirical experimentation, even as part of small experimental pilots. By following these two approaches and building on Levi (1991), this new pathway towards climate clubs and carbon neutrality may lead to a new global economic architecture through a "Low Carbon Bretton Woods".

\section{Acknowledgements}

The second author gratefully acknowledges the receipt of grant funding from the Centre for Research into Energy Demand Solutions, UK Research and Innovation, Grant agreement number EP/R035288/1

\section{References}

ADB (2019). Article 6 of the Paris Agreement: Drawing Lessons from the Joint Crediting Mechanism. Asian Development Bank November 2019, doi: http://dx.doi.org/10.22617/TIM190555-2.

Adler, D., Varoufakis, Y. (2019). The World Bank and IMF are in crisis. It's time to push a radical new vision. The Guardian, https://www.theguardian.com/commentisfree/2019/jan/31/world-bank-imfbretton-woods-banking-keynes

Aguedas Ortiz, D. (2020). 32 leading countries set benchmark for carbon markets with San Jose Principles. Direccion de Cambio Climatico. Press release, https://cambioclimatico.go.cr/pressrelease-leading-countries-set-benchmark-for-carbon-markets-with-san-jose-principles/

Anderson, T., Parker, D. (2013). Transaction Costs and Environmental Markets: The Role of Entrepreneurs. Review of Environmental Economics and Policy, 7(2): 259-275.

Asadnabizadeh, M. (2019). Development of UN Framework Convention on Climate Change Negotiations under COP25: Article 6 of the Paris Agreement perspective. Open Political Science, 2: 113-119.

Baranzini, A., Carattini, S. (2017). Effectiveness, earmarking and labelling: testing the acceptability of carbon taxes with survey data. Environmental Economics and Policy Studies, 19(1): 197-227.

Bendell, J. (2018). Deep Adaptation: A Map for Navigating Climate Tragedy. Institute for Leadership and Sustainability Occasional Paper 2. University of Cumbria: UK.

Birch, K. (2017). Rethinking Value in the Bio-economy: Finance, Assetization, and the Management of Value. Science, Technology, \& Human Values, 42(3): 460-490.

Blaxekjær, L., Nielsen, T. (2014). Mapping the narrative position of new political groups under the UNFCCC. Climate Policy, 15(6), 751-766. 
Blyth, W., Bunn, D., Kettunen, J., Wilson, T. (2009). Policy interactions, risk and price formation in carbon markets. Energy Policy, 37: 5192-5207.

Bowers, J. (1997). Sustainability and Environmental Economics: An Alternative Perspective. London, UK: Longman.

Button, J. (2008). Carbon: commodity or currency? The case for an international carbon market based on the currency model. Harvard Law Review, 32: 571-596.

Burgess, M. (2016). Personal carbon allowances: A revised model to alleviate distributional issues. Ecological Economics, 130: 316-327.

Calel, R. (2013). Carbon markets: a historical overview. WIREs Climate Change, 2013(4): 107-119.

Carbon Market Watch (2017). Building blocks for a robust Sustainable Development Mechanism. Carbon Market Watch Policy Brief, May 2017.

Chapron, G., 2017, The environment needs cryptogovernance, Nature, 545: 403-405.

Chen, D. (2018). Central Banks and Blockchains: The Case for Managing Climate Risk with Positive Carbon Price. In: Marke, A. (ed.), Transforming Climate Finance and Green Investment with Blockchain. Academic Press, London, 201-216.

Clark, J., Knox-Hayes, J. (2011). An Emerging Geography of Intangible Assets: Financialization in Carbon Emission Credit and Intellectual Property Markets. Georgia Institute of Technology: School of Public Policy Working Papers.

Clemençon, R. (2016). The two sides of the Paris climate agreement: Dismal failure or historic breakthrough? Journal of Environment and Development, 25(1), 3-24.

Cœuré, B. (2018). Monetary policy and climate change. Speech given at the conference on 'Scaling up Green Finance: The Role of Central Banks', Berlin 8 November 2018, https://www.ecb.europa.eu/press/key/date/2018/html/ecb.sp181108.en.html

Costa, L., Rybski, D., \& Kropp, J. P. (2011). A human development framework for CO2 reductions. PloS One, 6(12), 1-9.

Costanza, R., Kubiszewski, I., Giovannini, E., Lovins, H., McGlade, J., Pickett, K., Ragnarsdottir, K., Roberts, D., De Vogli, R., Wilkinson, R. (2014). Development: Time to leave GDP behind. Nature, 505(7483).

Das, K. (2015). Climate Clubs: Carrots, Sticks and More. Economic \& Political Weekly, 50(34): $24-27$.

Davidson, S., De Filippi, P., Potts, J. (2016). Economics of Blockchain. Fort Lauderdale: Proceedings of Public Choice Conference.

Dietzenbacher, E., Cazcarro, I., Arto, I. (2020). Towards a more effective climate policy on international trade. Nature Communication, https://doi.org/10.1038/s41467-020-14837-5.

Drews, S., van den Bergh, J. (2016). What explains public support for climate policies? A review of empirical and experimental studies. Climate Policy, 16(7): 855-876.

Dreyfuss, R., Frankel, S. (2015). From Incentive to Commodity to Asset: How International Law is Reconceptualising Intellectual Property. Michigan Journal of International Law, 36(4): 557-602.

EC (2019). The European Green Deal. https://eur-lex.europa.eu/legalcontent/EN/TXT/?qid=1588580774040\&uri=CELEX:52019DC0640 
Falkner, R. (2016). A minilateral solution for global climate change? On bargaining efficiency, club benefits and international legitimacy. Perspectives on Politics, 14(1): 87-101.

Fawcett, T. (2010). Personal carbon trading: A policy ahead of its time? Energy Policy, 38(11): 68686876).

Fawcett, T., Parag, Y. (2017). Personal Carbon Trading. Routledge: Abingdon.

Franke, L., Schletz, M., Salomo, S. (2020). Designing a Blockchain Model for the Paris Agreement's Carbon Market Mechanism. Sustainability, 12: 2068, doi:10.3390/su12031068.

Friedlingstein, P., Jones, M., O'Sullivan, M., Andrew, R., Hauck, J., Peter, G. et al. (2019). Global Carbon Budget 2019. Earth System Science Data, 11(2019): 1783-1838.

Gao, S., Li, M.-Y., Duan, M., Wang, C. (2019). International carbon markets under the Paris Agreement: Basic form and development prospects. Advances in Climate Change Research, 10(1): 21-29.

Greiner, S., Michaelowa, A. (2018). Cooperative approaches under Art. 6.2 of the Paris Agreement: Status of negotiations - key areas of consensus and contention. Discussion Paper - January 2018, https://climatefocus.com/sites/default/files/20180301\%20Discussion\%20Paper\%20\%20Cooperative\%20Approaches\%20consent\%20and\%20dissens\%5B1\%5D.pdf

Grubb, M. (2014). Planetary economics: energy, climate change and the three domains of sustainable development. Routledge: Abingdon.

Hixson, W. (1991). A Matter of Interest: Reexamining Money, Debt and Real Economic Growth. Praeger: New York.

IMF (2019). The Economics of Climate. Finance \& Development: 56(4).

IPCC (2018) Global Warming of $1.5^{\circ} \mathrm{C}$. Intergovernmental Panel on Climate Change. Cambridge University Press.

IPCC (2021). Climate Change 2021: The Physical Science Basis. Contribution of Working Group I to the Sixth Assessment Report of the Intergovernmental Panel on Climate Change. Cambridge University Press.

Keohane, N. Petsonk, A., Hanafi. A. (2017). Toward a club of carbon markets. Climatic Change, 144: 81-95.

Keynes, J. (1939). The process of capital formation. Economic Journal, 49: 569-575.

Kim, S.-K., Huh, J.-H. (2020). Blockchain of Carbon Trading for UN Sustainable Development Goals. Sustainability, 12: 4021.

Kragh-Furbo, M., Walker, G. (2018). Electricity as (Big) Data: Metering, spatiotemporal granularity and value. Big Data \& Society, January- June 2018: 1-12.

Lacroix, K., Richards, G. (2015). An alternative policy evaluation of the British Columbia carbon tax: broadening the application of Elinor Ostrom's design principles for managing common-pool resources. Ecology and Society, 20(2): 38

Leonelli, S. (2014). What difference does quantity make? On the epistemology of Big Data in biology. Big Data \& Society April-June 2014(1): 1-11.

Levi, M. (1991) Bretton Woods: Blueprint for a greenhouse gas agreement. Ecological Economics 4: 253-267. 
Li, M., Duan, M. (2020). Efforts-sharing to achieve the Paris goals: Ratcheting-up of NDCs and taking full advantage of international carbon market. Applied Energy, https://doi.org/10.1016/j.apenergy.2020.115864.

Lietaer, B. (2004). The Terra TMC TM White Paper. https://www.changemakers.com/sites/default/files/Terra WhitePaper final.pdf

Lietaer, B., Dunne, J. (2013) Rethinking Money: How new currencies turn scarcity into prosperity. Berrett-Koehler Publishers: San Francisco.

MacKenzie, D. (2009). Making things the same: Gases, emission rights and the politics of carbon markets. Accounting, Organizations and Society 34(3-4): 440-455.

Marcu, A. (2016). Carbon market provisions in the Paris Agreement (Article 6). CEPS Special Report 128, https://www.ceps.eu/wpcontent/uploads/2016/01/SR\%20No\%20128\%20ACM\%20Post\%20COP21\%20Analysis\%20of\%20Artic $\underline{\text { le\%206.pdf }}$

Mazzucato, M. (2018). Mission-oriented innovation policies: challenges and opportunities. Industrial and Corporate Change 27(5): 803-815

Mehling, M., van Asselt, H., Das, K., Droege, S. (2018). Beat Protectionism and Emissions at a Stroke. Nature 559(7714): 321-324.

Meyer, A. (2000). Contraction and convergence: The global solutions to climate change. Cambridge: Schumacher Briefings Paperback.

Michaelowa. A, (2019). Markets, ambition and finance - COP 25: too much on the plate.

Perspectives Climate Group,

https://www.perspectives.cc/fileadmin/Publications/COP25 Results Perspectives.pdf

Michaelowa, A., Hermwille, L., Obergassel, W., Butzengeiger, S. (2019) Additionality revisited: guarding the integrity of market mechanisms under the Paris Agreement. Climate Policy 19(10): 2111-1224.

Mueller, B., Michaelowa, A. (2019). How to operationalize accounting under Article 6 market mechanisms of the Paris Agreement. Climate Policy 19(7): 812-819.

Nolden, C., Stua, M. (2017). The Road to Paris. In: Stua M, From the Paris Agreement to a LowCarbon Bretton Woods. Cham, Switzerland: Springer International Publishing: 9-30.

Nolden, C., Stua, M. (2020). Carbon dating - Getting together to reduce carbon emissions brings hope in a world that doesn't care. The Mint, 13: 19-21.

Nordhaus, W. (2015). Climate Clubs: Overcoming Free-riding in International Climate Policy. American Economic Review, 105(4): 1339-1370.

Nordhaus, W. (2020). The Climate Club How to Fix a Failing Global Effort. Foreign Affairs, https://www.foreignaffairs.com/articles/united-states/2020-04-10/climate-club

North, D. (1990). Institutions, institutional change and economic performance. Cambridge:

Cambridge University Press.

OECD (2019). How can development co-operation align with the objectives of the Paris Agreement? https://doi.org/10.1787/5099ad91-en.

Pihl, H. (2020). A Climate Club as a complementary design to the UN Paris agreement. Policy Design and Practice, https://doi.org/10.1080/25741292.2019.1710911 
Rajamani, L. (2014). The Warsaw climate negotiations: Emerging understandings and battle lines on the road to the 2015 climate agreement. International and Comparative Law Quarterly, 63(3), 721740 .

Rajamani, L. (2016). Ambition and differentiation in the 2015 Paris Agreement: Interpretative possibilities and underlying politics. International and Comparative Law Quarterly, 65(2), 493-514.

Rajan, R. (2019). A fair and simple way to tax carbon emissions. Financial Times, https://www.ft.com/content/96782e84-2028-11ea-b8a1-584213ee7b2b

Raworth, K. (2017). Doughnut Economics: Seven Ways to Think Like a $21^{\text {st }}$ Century Economist. White River Junction, VT: Chelsea Green Publishing.

Rogelj, J., Schaeffer, M., Friedlingstein, P., Gillett, N., van Vurren, D., Riahi, K., Allen, M., Knutti, R. (2016). Differences between carbon budget estimates unravelled. Nature Climate Change 6: 245252.

Rogoff, K. (2019). It's high time to create a World Carbon Bank. The Guardian, https://www.theguardian.com/environment/2019/jul/08/world-carbon-bank-carbon-tax-kennethrogoff

Schletz, M., Franke, L., Salomo, S. (2020). Blockchain Application for the Paris Agreement Carbon Market Mechanism - A Decision Framework and Architecture. Sustainability, 12: 5069.

Schneider , L., La Hoz Theuer , S., Howard , A., Kizzier K., Cames, M. (2020) Outside in? Using international carbon markets for mitigation not covered by nationally determined contributions (NDCs) under the Paris Agreement. Climate Policy, 20:1, 18-29, DOI:10.1080/14693062.2019.1674628.

Sirkis, A., Hourcade, J.-C., Dasgupta, D., Studart, R., Gallagher, K., Perissin-Fabert, B. et al. (2015). Moving the trillions: A debate on positive pricing of mitigation actions. Rio de Janeiro: Brasil No Clima.

Sorrell, S. (2010). Energy, Economic Growth and Environmental Sustainability: Five Propositions. Sustainability 2: 1784-1809.

Sovacool, B., Geels, F. (2016). Further reflections on the temporality of energy transitions: a response to critics. Energy Research \& Social Science 22: 232-237.

Srinivasan, S., Sanchez, F. (2020). Unlocking ambition through a Climate Market Club. World Bank Blogs, https://blogs.worldbank.org/climatechange/unlocking-ambition-through-climate-market-club

Steffen, W., Richardson, K., Rockstroem, J., Cornell, S., Fetzer, I., Bennett, E. et al. (2015). Planetary boundaries: Guiding human development on a changing planet. Science 347(6223). DOI: 10.1126/science.1259855.

Steinebach Y.,Limberg, J. (2021). Implementing market mechanisms in the Paris era: the importance of bureaucratic capacity building for international climate policy, Journal of European Public Policy, DOI: 10.1080/13501763.2021.1925330

Stern, N. (2007). The Economics of Climate Change. Cambridge, UK: Cambridge University Press.

Stua, M. (2013). Evidence of the clean development mechanism impact on the Chinese electric power system's low-carbon transition. Energy Policy 62(2013): 1309-1319.

Stua, M. (2017a). From the Paris Agreement to a Low-Carbon Bretton Woods. Cham, Switzerland: Springer International Publishing. 
Stua, M. (2017b). A Transformational Club within the Paris Agreement: A Climate-Club Perspective on Article 6. In: Stavins R, Stowe R. Market Mechanisms and the Paris Agreement. Cambridge, MA: Harvard Project on Climate Agreements.

Stua, M., Coulon, M. (2017). The Mitigation Alliance Target and Its Distribution. In: Stua M, From the Paris Agreement to a Low-Carbon Bretton Woods. Cham, Switzerland: Springer International Publishing: 69-84.

Stua, M., Nolden, C., Coulon, M. (2019). Climate clubs and positive carbon pricing for a Low-Carbon Bretton Woods. University of Bristol Law Paper Research Series, \#004 2019.

Tooze, A. (2019). Why central banks need to step up on global warming. Foreign Policy, https://foreignpolicy.com/2019/07/20/why-central-banks-need-to-step-up-on-global-warming/

Tørstad, V. H. (2020). Participation, ambition and compliance: can the Paris Agreement solve the effectiveness trilemma? Environmental Politics 29(5): 761-780.

doi.org/10.1080/09644016.2019.1710322

UNEP (2018). Emission Gap Report 2018. Nairobi: United National Environment Programme.

UNEP (2019). Emissions Gap Report 2019. Nairobi: United Nations Environment Programme.

UNFCCC (1997). The Kyoto Protocol. Bonn: United Nations Framework Convention on Climate Change.

UNFCCC (2015). The Paris Agreement. Bonn: United Nations Framework Convention on Climate Change.

Varoufakis, Y. (2019). Imagining a new Keynesian Bretton Woods. World Economic Forum, https://www.weforum.org/agenda/2016/05/yanis-varoufakis-imagining-a-new-keynesian-brettonwoods

Veal, G., Mouzas, S. (2012). Market-Based Responses to Climate Change: $\mathrm{CO}_{2}$ Market Design versus Operation. Organization Studies 33(11): 1589-1616.

Von der Leyen, U. (2019). Mission Letter to Frans Timmermans - Executive Vice-President-designate for the European Green Deal. Brussels: European Commission.

Wei, Y.-M., Wang, L., Liao, H., Wang, K., Murty, T., Yan, J. (2014). Responsibility accounting in carbon allocation: A global perspective. Applied Energy, 130: 122-133.

Weischer, L., Morgan, J., Patel, M. (2012). Climate Clubs: Can Small Groups of Countries make a Big Difference in Addressing Climate Change? RECIEL, 21(3): 177-192.

Welch, D., Southerton, D. (2019). After Paris: transitions for sustainable consumption. Sustainability: Science, Practice and Policy, 15(1): 31-44.

World Bank (2018). Blockchain and Emerging Digital Technologies for Enhancing Post-2020 Climate Markets. Washington: World Bank.

Zaman, P. (2017). A Low Carbon Bretton Woods: A Legal Critique. In: Stua, M. From the Paris Agreement to a Low-Carbon Bretton Woods. Cham, Switzerland: Springer International Publishing, pp. 219-231.

Zhang, X., Löschel, A., Lewis, J., Zhang, D., Yan, J. (2020). Emissions trading systems for global low carbon energy and economic transformation. Applied Energy, https://doi.org/10.1016/j.apenergy.2020.115858. 
Zhao, F., Chan, W. K. (2020). When Is Blockchain Worth It? A Case Study of Carbon Trading. Energies, 13: 1980. 